\section{Advancing the Tamarillo Harvest by Induced Postharvest Ripening}

\author{
J. Prohens, J.J. Ruiz, and F. Nuez \\ Departamento de Biotecnología, Universidad Politécnica de Valencia, 46022 \\ Valencia, Spain
}

Additional index words. Cyphomandra betacea, tree tomato, maturity stage, temperature, ethephon, weight loss

\begin{abstract}
Tamarillo [Cyphomandra betacea (Cav.) Sendt., Solanaceae] dark-red-, red-, and yellow-type fruit were sorted into two maturity stages (green and turning); dipped in ethephon at $0,250,500$, or $750 \mathrm{mg}^{-l i t e r}{ }^{-1}$; and kept at 18 or $28 \mathrm{C}$. Seven days later, fruit dipped in ethephon at 500 or $750 \mathrm{mg}^{-l i t e r^{-1}}$ and stored at $28 \mathrm{C}$ showed a color score, maturity index, and ascorbic acid content similar to those tree-ripened, thus making it possible for harvesting to be advanced 36 days. Under these conditions, weight loss was always lower than $8.5 \%$, resulting in only slight symptoms of shriveling that did not affect commercial quality. Postharvest ripening reduces the risk of crop failure, increases earliness, and concentrates harvesting. Chemical name used: (2-chloroethyl)phosphonic acid (ethephon).
\end{abstract}

Tamarillo or tree tomato is a fast-growing, small tree native to South America. It is grown as a commercial crop in some Andean countries, New Zealand, and occasionally in Florida and California (Duke and duCellier, 1993). Tamarillo appears to have a bright future; its fruit are now becoming familiar in grocery stores as a specialty (Bohs, 1988). They can be eaten raw as a fruit or cut up in salads. Tamarillos also can be made into sauces, juices, jams, ice creams, and other desserts. There are apparently no named varieties, but three types are distinguished according to fruit color: darkred, red, and yellow (National Research Council, 1989). The dark-red type is said to be much superior to the others. This large and higher quality type was developed in New Zealand around 1920 from material from Loja, Ecuador (Heiser, 1984; Morton, 1982).

In its original environment and in other climates with little climatic variations between seasons, tamarillo sets throughout the year (Azad-Thakur et al., 1988; Duke and duCellier, 1993; National Research Council, 1989). However, many references show that, in Mediterranean climates, flowering takes place in spring, while fruit ripening occurs in autumn or winter (Carnevali, 1974; Pileri, 1989; Rotundo et al., 1981). We also have noticed this behavior (unpublished data). After full size is attained, fruit ripening can take up to 10 or more weeks (Heatherbell et al., 1982; Pratt and Reid, 1976). Thus, the tree is heavily laden during the ripening season, which increases risk of crop failure and tree damage since laden branches are easily broken by gusts of wind (Carnevali, 1974; Morton, 1982; National Research Council, 1989). An effective system that would

Received for publication 16 May 1995. Accepted for publication 2 Oct. 1995. The cost of publishing this paper was defrayed in part by the payment of page charges. Under postal regulations, this paper therefore must be hereby marked advertisement solely to indicate this fact. allow harvesting when fruit reach full size, followed by postharvest ripening, would not only contribute to reduce these risks, but it would also increase earliness, concentrate harvest, and presumably improve the next flowering.

Respiration and ethylene studies identified red tamarillo fruit as nonclimacteric (Pratt and Reid, 1976). Espina and Lizana (1991) pointed out that red tamarillos maintained constant $\mathrm{pH}$, soluble solids concentration (SSC), and acidity values after storage for 15 or 35 days at 0 or 7C. However, El-Zeftawi et al. (1988) found that dark-red tamarillos continued to ripen after harvest, becoming softer and juicier, and suggested harvesting when fruit are purple (mature stage).

Some previous experiments have suggested that postharvest treatment with ethylene can ripen tamarillos when it is not possible to let them ripen naturally on the tree. Continuous ethylene treatment at $100 \mathrm{mg}^{\circ}$ liter $^{-1}$ or higher for several days hastened senescence of red strain fruit of all ages (Pratt and Reid, 1976). Fruit treated with ethylene became soft and developed yellow flesh. El-Zeftawi etal. (1988) also noted that dipping in ethephon at 500 mg.liter ${ }^{-1}$ increased the color and SSC and improved the flavor of dark-red tamarillos stored for 21 days at 18 to $20 \mathrm{C}$.

Our experiment was conducted to determine if it is possible to ripen tamarillo fruit, which have been harvested several weeks before attaining commercial ripening, after harvest with minimal loss in commercial quality compared to tree-ripened fruit.

\section{Materials and Methods}

Tamarillo dark-red-, red-, and yellow-type (strains ECU-231, ECU-140, and ECU-155, respectively) fruit were obtained from 2year-old trees grown on an experimental field at the Universidad Politécnica de Valencia. These strains were collected from commercial orchards in Ecuador (Nuez et al., 1993).
Full-sized tamarillos were tagged on the tree on 5 Sept. 1994. On the following day, some fruit were picked and brought to the laboratory while the others were left on the tree. Fruit were sorted on the basis of skin color into two maturity stages: green, when the skin was entirely green, and turning, when the green ground color of the skin was fading and an incipient ripe color characteristic of each type became apparent in the part of the fruit most exposed to the sun. Some of the harvested fruit were analyzed immediately, while the others were weighed and dipped in an ethephon solution at $0,250,500$, or 750 $\mathrm{mg} \cdot \mathrm{liter}^{-1}$ for $10 \mathrm{sec}$; Tween $20(0.1 \% \mathrm{v} / \mathrm{v})$ was used as a wetting agent. Fruit were allowed to air-dry at the laboratory temperature and then were placed at 18 or $28 \mathrm{C}$ and $90 \%$ relative humidity. All stored fruit were analyzed when some treatments had reached the commercial ripeness stage (fully colored and somewhat soft), which occurred 1 week after picking. Fruit left on the tree were picked and analyzed on 12 Oct. At about this time, fruit tagged as turning on 5 Sept. had reached commercial ripeness stage.

All assessments were conducted on fivefruit samples of six replications in a completely randomized design. Just before the analysis, fruit samples were weighed and fruit color was scored using a 1 to 5 scale with 0.5 increments $(1=$ entirely green, $5=$ fully colored). Color photographs of five tamarillos from each strain ranging from score 1 to 5 were used as a standard to assess fruit color. Fruit with a color score equal or superior to 4 are considered commercial, but fruit with a color score of 4.5 or 5 are preferred. Immediately after the fruit had been juiced using a domestic juice extractor, ascorbic acid was determined using metaphosphoric acid extraction and 2,6dichlorophenolindolephenol dye reduction. SSC (percent) was measured using a handheld refractometer. Titratable acidity was determined by titrating diluted juice with $0.1 \mathrm{~N}$ $\mathrm{NaOH}$ to the phenolphthalein-end point. Results are presented as percent anhydrous citric acid since this is the main acid in tamarillo fruit (Romero-Rodriguez et al., 1994). From these values, a maturity index (MI) was calculated as the SSC : acidity ratio.

Factorial analysis of variance with maturity stage, storage temperature, and ethephon dose as independent factors were performed on the data of stored fruit.

\section{Results}

On-tree ripening. Natural ripening increased skin color score, MI, and ascorbic acid concentration (AAC), while fruit weight was maintained (Table 1). Increases in MI were due to a decrease in acidity and an increase in SSC (data not shown).

Postharvest ripening. Skin color was affected by all factors studied (Table 2). Green and turning fruit showed an increase in color score with ethephon applications, with higher values at the higher doses of ethephon, but for red and yellow strains, the absolute increase when treated with the $250 \mathrm{mg}$ ethephon/liter 
Table 1. Characteristics of tamarillo fruit graded as green or turning on 5 Sept. and harvested on 6 Sept. or 12 Oct. (when fruit that were turning on 6 Sept. had reached commercial ripeness stage). ${ }^{2}$

\begin{tabular}{|c|c|c|c|c|}
\hline \multirow[b]{2}{*}{ Characteristic } & \multicolumn{2}{|c|}{6 Sept. } & \multicolumn{2}{|c|}{12 Oct. } \\
\hline & Green fruit & Turning fruit & Green fruit & Turning fruit \\
\hline \multicolumn{5}{|c|}{ Dark-red strain } \\
\hline Color score & $1.00 \pm 0.00$ & $2.00 \pm 0.00$ & $3.58 \pm 0.15$ & $4.92 \pm 0.08$ \\
\hline $\mathrm{MI}^{\mathrm{y}}$ & $3.60 \pm 0.16$ & $4.98 \pm 0.25$ & $5.82 \pm 0.26$ & $7.12 \pm 0.53$ \\
\hline Ascorbic acid (mg/100 g) & $21.2 \pm 2.4$ & $23.5 \pm 1.6$ & $24.3 \pm 2.5$ & $26.1 \pm 3.3$ \\
\hline Fruit weight $(\mathrm{g})$ & $60.1 \pm 0.7$ & $64.6 \pm 0.7$ & $63.5 \pm 2.6$ & $66.4 \pm 2.7$ \\
\hline \multicolumn{5}{|c|}{ Red strain } \\
\hline Color score & $1.00 \pm 0.00$ & $2.00 \pm 0.00$ & $3.00 \pm 0.13$ & $4.50 \pm 0.18$ \\
\hline MI & $3.07 \pm 0.05$ & $3.80 \pm 0.08$ & $5.16 \pm 0.19$ & $6.28 \pm 0.14$ \\
\hline Ascorbic acid (mg/100 g) & $15.1 \pm 1.2$ & $18.6 \pm 2.2$ & $21.6 \pm 1.6$ & $22.4 \pm 3.3$ \\
\hline Fruit weight $(\mathrm{g})$ & $47.0 \pm 1.0$ & $51.2 \pm 0.8$ & $49.6 \pm 2.7$ & $49.7 \pm 1.3$ \\
\hline \multicolumn{5}{|c|}{ Yellow strain } \\
\hline Color score & $1.00 \pm 0.00$ & $2.00 \pm 0.00$ & $3.67 \pm 0.10$ & $4.58 \pm 0.20$ \\
\hline MI & $3.06 \pm 0.08$ & $4.98 \pm 0.02$ & $4.92 \pm 0.30$ & $6.62 \pm 0.44$ \\
\hline Ascorbic acid (mg/100 g) & $19.9 \pm 2.1$ & $21.9 \pm 1.8$ & $22.7 \pm 2.5$ & $25.1 \pm 1.3$ \\
\hline Fruit weight $(\mathrm{g})$ & $44.1 \pm 0.5$ & $48.2 \pm 0.7$ & $44.8 \pm 1.3$ & $46.7 \pm 1.5$ \\
\hline
\end{tabular}

$\overline{{ }^{2} \text { Values are means of six samples } \pm \text { SE, except for fruit weight on } 6 \text { Sept. in which data were taken on } 54}$ samples.

${ }^{\mathrm{y}} \mathrm{MI}=$ maturity index.

Table 2. Effect of maturity stage, storage temperature, and ethephon on color score $(1=$ entirely green, $5=$ fully colored) in tamarillo fruit after 7 days of storage.

\begin{tabular}{|c|c|c|c|c|c|c|}
\hline \multirow{2}{*}{$\begin{array}{l}\text { Ethephon } \\
\left(\mathrm{mg} \cdot \text { liter }^{-1}\right)\end{array}$} & \multicolumn{2}{|c|}{ Dark-red strain } & \multicolumn{2}{|c|}{ Red strain } & \multicolumn{2}{|c|}{ Yellow strain } \\
\hline & $18 \mathrm{C}$ & $28 \mathrm{C}$ & $18 \mathrm{C}$ & $28 \mathrm{C}$ & $18 \mathrm{C}$ & 280 \\
\hline \multicolumn{7}{|c|}{ Green fruit } \\
\hline 0 & 1.00 & 1.17 & 1.00 & 1.00 & 1.00 & 1.00 \\
\hline 250 & 1.83 & 2.83 & 1.75 & 2.00 & 1.92 & 2.17 \\
\hline 500 & 2.92 & 3.25 & 2.92 & 2.83 & 3.00 & 3.08 \\
\hline 750 & 3.00 & 3.67 & 3.00 & 3.33 & 3.00 & 3.92 \\
\hline \multicolumn{7}{|c|}{ Turning fruit } \\
\hline 0 & 2.00 & 2.00 & 2.00 & 2.33 & 2.00 & 2.00 \\
\hline 250 & 3.67 & 3.75 & 3.58 & 4.00 & 3.50 & 4.17 \\
\hline 500 & 4.33 & 4.83 & 3.75 & 4.08 & 4.00 & 4.33 \\
\hline 750 & 4.42 & 4.92 & 4.00 & 4.33 & 4.08 & 4.58 \\
\hline Significance & & & & & & \\
\hline Maturity stage (M) & \multicolumn{2}{|c|}{$* * *$} & \multicolumn{2}{|c|}{$* * *$} & \multicolumn{2}{|c|}{$* * *$} \\
\hline Temperature $(\mathrm{T})$ & \multicolumn{2}{|c|}{$* *$} & \multicolumn{2}{|c|}{$* *$} & \multicolumn{2}{|c|}{$* * *$} \\
\hline Ethephon (E) & \multicolumn{2}{|c|}{$\mathrm{L}^{* * *}, \mathrm{Q}^{* * *}$} & \multicolumn{2}{|c|}{$\mathrm{L}^{* * *}, \mathrm{Q}^{* * *}$} & \multicolumn{2}{|c|}{$\mathrm{L}^{* * *}, \mathrm{Q}^{* * *}$} \\
\hline $\mathrm{M} \times \mathrm{T}$ & \multicolumn{2}{|c|}{ NS } & \multicolumn{2}{|c|}{$\begin{array}{l}\mathrm{NS} \\
* * *\end{array}$} & \multicolumn{2}{|c|}{ NS } \\
\hline $\mathrm{M} \times \mathrm{E}$ & \multicolumn{2}{|c|}{ NS } & \multirow{2}{*}{\multicolumn{2}{|c|}{$\begin{array}{c}* * * \\
\text { NS }\end{array}$}} & \multicolumn{2}{|c|}{$* * *$} \\
\hline $\mathrm{T} \times \mathrm{E}$ & \multicolumn{2}{|c|}{ NS } & & & \multirow{2}{*}{\multicolumn{2}{|c|}{$* *$}} \\
\hline $\mathrm{M} \times \mathrm{T} \times \mathrm{E}$ & \multicolumn{2}{|c|}{ NS } & \multicolumn{2}{|c|}{ NS } & & \\
\hline
\end{tabular}

was higher for turning than for green fruit, although in most cases, the percent increase was the same (Table 2). Storage temperature also influenced response to ethephon in the yellow strain: fruit kept at $28 \mathrm{C}$ had a greater increase in color score with higher ethephon doses, while at $18 \mathrm{C}$, there was saturation at the highest doses.

Ethephon effect on MI was influenced by maturity stage and storage temperature (Table $3)$. Green fruit showed an increase in MI value with increasing ethephon doses. Response to treatment with $250 \mathrm{mg}$ ethephon/ liter was high for turning fruit, but it reached saturation with the 500 - or 750 -mg.liter ${ }^{-1}$ doses. Thus, the higher response was at the higher doses of ethephon. The MI of red and yellow strains increased more for turning than for green fruit at the higher temperature. As with natural ripening, increases in MI were due to a decrease in acidity and an increase in SSC (data not shown). However, decreases in the MI at the highest ethephon dose were only due to a decrease in SSC (data not shown).

AAC was influenced by ethephon applications and storage temperature (Table 4). There was an increase in AAC with increasing ethephon doses. Storage temperature affected the AAC in red and yellow strains, which showed a higher concentration after storage at $18 \mathrm{C}$ than at $28 \mathrm{C}$.

Weight loss percentage ranged from $2.5 \%$ to $3.4 \%$ at $18 \mathrm{C}$ and from $6.6 \%$ to $8.5 \%$ at $28 \mathrm{C}$, regardless of the strain, maturity stage, and ethephon dose combination. However, mean weight loss was lower for the dark-red strain $(4.8 \%)$ than for red or yellow strains $(5.4 \%$ in both cases).

\section{Discussion}

As has been described for many other fruit, exogenous applications of ethephon stimulated postharvest ripening of tamarillos. The fact that ethephon can accelerate so many ripening processes in nonclimacteric fruit has been ascribed to nonspecific effects on membrane permeability (Elkashif and Huber, 1988).

Fruit stored at $28 \mathrm{C}$ ripened more quickly than those stored at $18 \mathrm{C}$. This is probably related to reduced activity in biological processes at $18 \mathrm{C}$, along with a decreased rate of absorption and degradation of ethephon (Beaudry and Kays, 1987; Flore and Bukovac, 1982).

Turning fruit reached a skin ground color similar to those tree-ripened (Table 1). However, green fruit treated with ethephon only developed a pale ground color, which would make them commercially unacceptable. Even when green ethephon-treated fruit were left in storage until the appearance of decay, the color did not increase further (unpublished data). Postharvest fruit color development is probably a result of chlorophyll degradation without de novo anthocyanin biosynthesis. Chlorophyll content decreases during storage in green fruit (El-Zeftawi et al., 1988), but there is no additional anthocyanin pigment development in the skin in response to treatment with ethylene (Pratt and Reid, 1976). However, anthocyanin content of the skin barely increases in the 4 to 6 weeks before commercial ripening stage is attained (ElZeftawi et al., 1988; Heatherbell et al., 1982).

Postharvest increases found in the MI are in accordance with the increase in SSC and the decrease in acidity during storage as reported by El-Zeftawi et al. (1988). Lack of variation in ripening traits during postharvest storage found by Espina and Lizana (1991) probably were related to the low storage temperatures used ( 0 and $7 \mathrm{C})$. These temperatures would inhibit most biological processes. Similar increases in AAC to those found in this experiment as a result of ethephon treatment have been reported in tomato following ethylene gassing (Watada et al., 1976).

The low weight loss of the dark-red strain is likely a consequence of its larger size. For most fruit and vegetables, the higher the ratio of surface area to unit volume, the greater the loss of water (Salunkhe and Desai, 1984).

After 7 days in storage, fruit of all treatment combinations looked good, especially when stored at 18C. Even when stored at 28C, weight loss did not surpass $8.5 \%$ in any case, resulting in slight shriveling symptoms that presumably would not have affected salability excessively. In other fruit, similar weight losses caused none to moderate shriveling symptoms (Hruschka, 1977). Although weight loss was much lower at $18 \mathrm{C}$, ripening at $28 \mathrm{C}$ seems advantageous since it is faster and the increase in $\mathrm{MI}$ value per $1 \%$ weight loss was higher at $28 \mathrm{C}(0.23)$ than at $18 \mathrm{C}(0.20)$.

The green stage appears to be physiologically too early for fruit to be ripened after harvest. Although they ripened somewhat, weight loss along with the lack of ripe color when allowed to ripen for a longer period would make them unmarketable. El-Zeftawi et al. (1988) found weight loss as high as $20 \%$ in green fruit stored for 14 days at 20C. Weight losses of this magnitude are completely unacceptable for trade purposes. 
Table 3. Effect of maturity stage, storage temperature, and ethephon on the maturity index (MI) of tamarillo fruit after 7 days of storage.

\begin{tabular}{|c|c|c|c|c|c|c|}
\hline \multirow{2}{*}{$\begin{array}{l}\text { Ethephon } \\
\left(\mathrm{mg} \cdot \text { liter }^{-1}\right)\end{array}$} & \multicolumn{2}{|c|}{ Dark-red strain } & \multicolumn{2}{|c|}{ Red strain } & \multicolumn{2}{|c|}{ Yellow strain } \\
\hline & $18 \mathrm{C}$ & $28 \mathrm{C}$ & $18 \mathrm{C}$ & $28 \mathrm{C}$ & $18 \mathrm{C}$ & $28 \mathrm{C}$ \\
\hline \multicolumn{7}{|c|}{ Green fruit } \\
\hline 0 & 3.52 & 4.32 & 2.94 & 3.23 & 3.04 & 3.44 \\
\hline 250 & 4.01 & 5.23 & 3.26 & 3.81 & 3.42 & 4.36 \\
\hline 500 & 4.10 & 5.28 & 3.53 & 4.45 & 3.97 & 4.83 \\
\hline 750 & 4.28 & 5.72 & 3.88 & 4.66 & 4.43 & 5.24 \\
\hline \multicolumn{7}{|c|}{ Turning fruit } \\
\hline 0 & 4.67 & 5.55 & 3.93 & 4.30 & 4.78 & 5.39 \\
\hline 250 & 5.68 & 5.90 & 5.02 & 6.10 & 5.53 & 7.91 \\
\hline 500 & 6.08 & 7.44 & 4.94 & 6.93 & 6.32 & 7.92 \\
\hline 750 & 5.56 & 6.97 & 5.43 & 7.36 & 5.71 & 8.13 \\
\hline \multicolumn{7}{|l|}{ Significance } \\
\hline Maturity stage (M) & \multicolumn{2}{|c|}{$* * *$} & \multicolumn{2}{|c|}{$* * *$} & \multicolumn{2}{|c|}{$* * *$} \\
\hline Temperature $(\mathrm{T})$ & \multicolumn{2}{|c|}{$* * *$} & \multicolumn{2}{|c|}{$* * *$} & \multicolumn{2}{|c|}{$* * *$} \\
\hline Ethephon (E) & \multicolumn{2}{|c|}{$\mathrm{L}^{* * *}, \mathrm{Q}^{* * *}$} & \multicolumn{2}{|c|}{$\mathrm{L}^{* * * *}, \mathrm{Q}^{* * *}$} & \multicolumn{2}{|c|}{$\mathrm{L}^{* * *}, \mathrm{Q}^{* * *}$} \\
\hline $\mathrm{M} \times \mathrm{T}$ & \multicolumn{2}{|c|}{ NS } & \multicolumn{2}{|c|}{$* * *$} & \multicolumn{2}{|c|}{$* * *$} \\
\hline $\mathrm{M} \times \mathrm{E}$ & \multicolumn{2}{|c|}{$* *$} & \multicolumn{2}{|c|}{$* * *$} & \multicolumn{2}{|c|}{$*$} \\
\hline $\mathrm{T} \times \mathrm{E}$ & \multicolumn{2}{|c|}{ NS } & \multicolumn{2}{|c|}{$* * *$} & \multicolumn{2}{|c|}{$* *$} \\
\hline $\mathrm{M} \times \mathrm{T} \times \mathrm{E}$ & \multicolumn{2}{|c|}{ NS } & \multicolumn{2}{|c|}{ NS } & \multicolumn{2}{|c|}{ NS } \\
\hline
\end{tabular}

Table 4. Effect of maturity stage, storage temperature, and ethephon on ascorbic acid concentration (milgram per $100 \mathrm{~g}$ ) in tamarillo fruit after 7 days of storage.

\begin{tabular}{|c|c|c|c|}
\hline Treatments & Dark-red strain & Red strain & Yellow strain \\
\hline \multicolumn{4}{|l|}{$\overline{\text { Maturity stage (M) }}$} \\
\hline Green & 21.5 & 19.3 & 19.6 \\
\hline Turning & 23.4 & 19.2 & 20.2 \\
\hline \multicolumn{4}{|l|}{ Temperature $(\mathrm{T})$} \\
\hline $18 \mathrm{C}$ & 22.1 & 21.3 & 21.2 \\
\hline $28 \mathrm{C}$ & 22.8 & 17.2 & 18.6 \\
\hline \multicolumn{4}{|l|}{ Ethephon (mg.liter-1) } \\
\hline 0 & 20.1 & 16.3 & 17.0 \\
\hline 250 & 20.8 & 18.5 & 18.0 \\
\hline 500 & 23.3 & 19.8 & 20.7 \\
\hline 750 & 25.7 & 22.4 & 23.8 \\
\hline \multicolumn{4}{|l|}{ Significance } \\
\hline Maturity stage (M) & NS & NS & NS \\
\hline Temperature $(\mathrm{T})$ & NS & $* *$ & $*$ \\
\hline Ethephon (E) & $\mathrm{L}^{* * *}, \mathrm{Q}^{\mathrm{Ns}}$ & $\mathrm{L}^{* * *}, \mathrm{Q}^{\mathrm{Ns}}$ & $\mathrm{L}^{* * *}, \mathrm{Q}^{\mathrm{Ns}}$ \\
\hline $\mathrm{M} \times \mathrm{T}$ & NS & NS & NS \\
\hline $\mathrm{M} \times \mathrm{E}$ & NS & NS & NS \\
\hline $\mathrm{T} \times \mathrm{E}$ & NS & NS & NS \\
\hline $\mathrm{M} \times \mathrm{T} \times \mathrm{E}$ & NS & NS & NS \\
\hline
\end{tabular}

We have shown that harvesting at the turning stage, storage at $28 \mathrm{C}$, and treatment with ethephon at 500 or $750 \mathrm{mg} \cdot \mathrm{liter}^{-1}$ allowed turning tamarillo fruit to ripen in 7 days, reaching levels similar to those treeripened for the characters studied. This feature allows harvesting to be advanced by $>1$ month. Postharvest treatment with ethephon or ethylene to hasten ripening may contribute not only to a decreased risk of crop failure because of the advancement in the harvesting dates, but also to the ability to offer this fruit to the consumer at earlier dates, thus improving its marketability.

\section{Literature Cited}

Azad-Thakur, N.S., Y.P. Sharma, and R.N. Barwal. 1988. Tree-tomato cultivation in Meghalaya. Indian Farming 37(2):3.

Beaudry, R.M. and S.J. Kays. 1987. Effects of physical and environmental factors on the release kinetics of ethylene from (2-chloroethyl) phosphonic acid and 2-(chloroethyl)methylbis(phenylmethoxy)silane. J. Amer. Soc. Hort. Sci. 112:352-359.

Bohs, L. 1988. Ethnobotany of the genus Cyphomandra (Solanaceae). Econ. Bot. 43:143163.

Carnevali, A. 1974. Il tamarillo: Una nuova possibilità per la frutticoltura meridionale. Frutticoltura 36(10/11):31-37.

Duke, J.A. and J.L. duCellier. 1993. Handbook of alternative cash crops. CRC Press, Boca Raton, Fla.

Elkashif, M.E. and D.J. Huber. 1988. Electrolyte leakage, firmness, and scanning electron microscopic studies of watermelon treated with ethylene. J. Amer. Soc. Hort. Sci. 113:378-381.

El-Zeftawi, B.M., L. Brohier, L. Dooley, F.H. Goubran, R. Holmes, and B. Scott. 1988. Some maturity indices for tamarillo and pepino fruits. J. Hort. Sci. 63:163-169.

Espina, S. and L.A. Lizana. 1991. Comportamiento de tamarillo (Cyphomandra betacea (Cav.) Sendtner) en almacenaje refrigerado. Proc. Interamer. Soc. Trop. Hort. 35:285-290.

Flore, J.A. and M.J. Bukovac. 1982. Factors influencing absorption of ${ }^{14} \mathrm{C}$-(2-chloroethyl) phosphonic acid by leaves of cherry. J. Amer. Soc. Hort. Sci. 107:965-968.

Heatherbell, D.A., M.S. Reid, and R.E. Wrolstad. 1982. The tamarillo: Chemical composition during growth and maturation. N.Z. J. Sci. 25:239243.

Heiser, C.B., Jr. 1984. The ethnobotany of the neotropical Solanaceae, p. 48-52. In: G.T.Prance and J.A. Kallunki (eds.). Ethnobotany in the neotropics. New York Botanical Garden, New York.

Hruschka, H.W. 1977. Postharvest weight loss and shrivel in five fruits and five vegetables. Mktg. Res. Rpt. U.S. Dept. Agr. 1059.

Morton, J.F. 1982. The tree tomato, or "tamarillo", A fast growing, early-fruiting small tree for subtropical climates. Proc. Fla. State Hort. Soc. 95:81-85.

National Research Council. 1989. Lost crops of the Incas: Little-known plants of the Andes with promise for worldwide cultivation. National Academy Press, Washington, D.C.

Nuez, F., R. Morales, J.J. Ruiz, P. Fernández de Córdova, E. Valdivieso, and F. González. 1993. Recolección de especies hortícolas en Ecuador. Plant Genetic Resources Nwsl. 96:29-33.

Pileri, A.M. 1989. Il tamarillo. Rivista di Frutticoltura 51(11):67-70.

Pratt, H.K. and M.S. Reid. 1976. The tamarillo: Fruit growth and maturation, ripening, respiration, and the role of ethylene. J. Sci. Food Agr. 27:399-404.

Romero-Rodriguez, M.A., M.L. Vazquez-Ochoa, J. Lopez-Hernandez, and J. Simal-Lozano. 1994. Composition of babaco, feijoa, passion-fruit and tamarillo produced in Galicia (NW Spain). Food Chem. 49:251-255.

Rotundo, A., C. Raffone, and S. Rotundo. 1981. Una prova di coltura del tamarillo in Campania. Frutticoltura 43(6):41-46.

Salunkhe, D.K. and B.B. Desai. 1984. Postharvest biotechnology of vegetables. vol. I. CRC Press, Boca Raton, Fla.

Watada, A.E., B.B. Aulenbach, and J.T. Worthington. 1976. Vitamins A and $\mathrm{C}$ in ripe tomatoes as affected by stage of ripeness at harvest and by supplementary ethylene. J. Food Sci. 41:856-858. 